
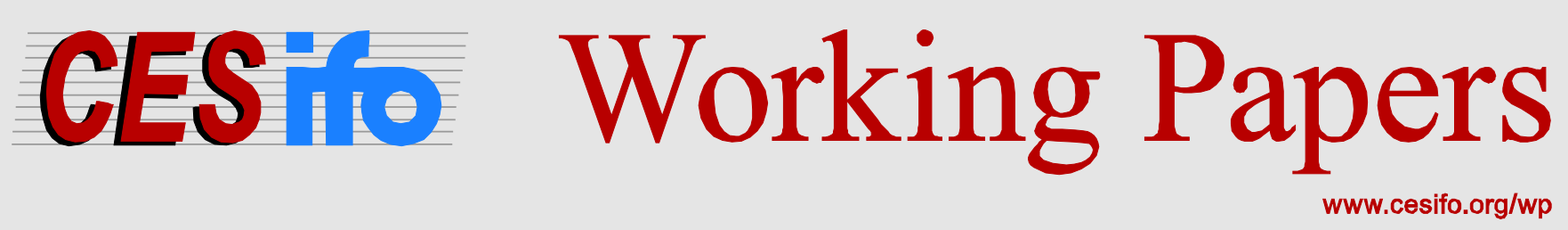

\title{
Contributive Pensions and Imperfect Tax Compliance: A Political Economy Model
}

\author{
Marie-Louise Leroux \\ Dario Maldonado \\ Pierre Pestieau
}

CESIFO WORKING PAPER NO. 5656

CATEgory 3: Social Protection

ORIGINAL VERSION: DECEMBER 2015

THIS VERSION: JUNE 2018

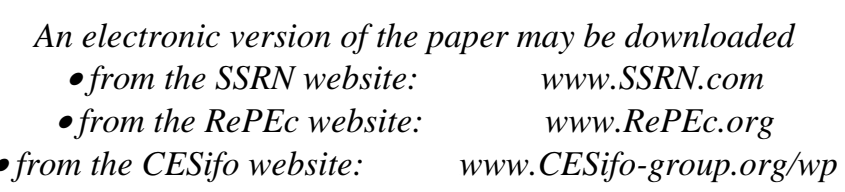

ISSN 2364-1428

CESifo 


\title{
Contributive Pensions and Imperfect Tax Compliance: A Political Economy Model
}

\begin{abstract}
This paper sheds light on the role of public institutions as a way to reduce tax evasion through a close link between payroll taxation and pension benefits. We use a political economy model in which agents have the possibility to hide part of their earnings in order to avoid taxation. Taxation is exclusively used to finance a pension benefit which is partly redistributive. We show that in the absence of evasion costs, agents are indifferent to the tax rate level as they can always perfectly adapt compliance so as to face their preferred effective tax rate. There is unanimity in favour of the maximum tax rate and, the public pension system is found to be contributory in order to increase compliance and thus the resources collected, which in turn enable higher redistribution toward the worst-off agents. When evasion costs are introduced, perfect substitutability between compliance and taxation breaks down. The majority voting equilibrium is such that individuals at the bottom of the income distribution who are in favour of more redistribution, and those at the top who want to transfer more resources to the old age, form a coalition against middle-income agents, in favour of high tax rates. In addition to the tax base argument, the optimal level of the Bismarkian pillar will now be chosen so as to account for increased political support.
\end{abstract}

JEL-Codes: H550, D780, D910.

Keywords: evasion costs, majority voting, public pensions, tax compliance.

\author{
Marie-Louise Leroux* \\ Département des Sciences Économiques \\ ESG-UQAM \\ Montréal / Québec / Canada \\ leroux.marie-louise@uqam.ca
}

\author{
Dario Maldonado \\ Universidad do los Andes \\ School of Government \\ Bogotá / Colombia \\ dmaldonadoc@uniandes.edu.co
}

\author{
Pierre Pestieau \\ Department of Economics \\ Université de Liège \\ Belgium - 4000 Liège \\ p.pestieau@ulg.ac.be
}

*corresponding author

June 5, 2018

We would like to thank Philippe De Donder as well as participants to the Société Canadienne de Sciences Economiques Conference in Québec (May 2016), for their comments and suggestions on this paper. 


\section{Introduction}

Tax evasion is endemic in many countries, in particular in developing countries, which do not collect even half of what they should if taxpayers complied with the written letter of the law (Moore and Mascagni, 2014). In these countries, enforcement mechanisms are weak, tax-collecting authorities are held in low esteem, and courts may not enforce the rules. Many developing countries still face tax shares of GDP below $15 \%$, which is considered as a reasonable threshold level for ensuring government functioning. ${ }^{1}$ In recent years, domestic revenue mobilization in developing countries has gained increasing prominence in the policy debate. This is due to several factors, including the potential benefits of taxation for state building, long-term independence from foreign assistance and, the continuing acute financial needs of developing countries.

Plenty of specific solutions to how boosting compliance have been offered in the literature and public authorities have tried many more. Some of them consist in increasing and in focusing better enforcement, in improving the collection and management of information, in reducing the costs of complying with the law, and in providing incentives for those who comply. ${ }^{2}$ The solution we explore in this paper consists in establishing a close link between the amount of taxes paid and the payments obtained in return. After all, if that link were perfect there would not be any problem of compliance and the tax would play the same role as any market price. Yet, in many countries, this link is often not perfect as the government is expected to provide public goods and redistribute income. This is the avenue of research this paper pursues.

The objective of our paper is therefore to focus on payroll taxation and to study how a government that uses a PAYGO pension system to redistribute towards the olds and the poor, must design it when it faces contribution evasion and political restrictions on the tax rate. Importantly, we assume that the proceeds of taxation need to be spent in (semi-)private goods which are not perfect substitutes to standard consumption but are essential to the individuals' welfare. Here, individuals will receive public pension benefits which depend (imperfectly) on their earlier tax payments. These benefits are essential to the individuals and have imperfect substitutes in the private sector because of either the absence of private annuity markets or the inefficiency of the financial sector. It should therefore be in the agents' own interest to contribute. ${ }^{3}$

We assume a two-period model, in which individuals work in the first period and retire in the second

\footnotetext{
${ }^{1}$ For instance, Gaspar et al. (2016) show that a minimum tax to GDP ratio (what they call a "tipping point") of $12.5 \%$ is needed to insure significant growth.

${ }^{2}$ Castro and Scartascini (2013) also explores the impact of the use of messages for affecting taxpayers' compliance by conducting a large-scale field experiment in Argentina. These messages operate on the beliefs and moral values that people attach to paying taxes.

${ }^{3}$ In our paper, we model old-age security, but we could as well have modelled other public goods such as health care, education or housing, as soon as claimed benefits depend at least partially on individual payments.
} 
one. In the first period, they choose how much income to report to fiscal authorities and pay a tax which depend on their reported amount so as to finance the pension system. They further allocate their income net of tax between current consumption and private saving. We assume also that not complying with the law may entail a moral cost (if, for instance, the social stigma of not complying with the fiscal law is important). ${ }^{4}$ The period of retirement is uncertain as a fraction of individuals do not survive after the first period. In the second period, individuals' consumption is financed by private saving and by the public pension benefit. As in Casamatta et al. (2000a,b), it depends on two components. The first one is proportional to their reported labor income; the factor of proportionality is called the Bismarkian factor. The second component, the Beveridgian part, is common to all individuals and depends on average tax collection. We also assume that there is a probability that the government defaults and is not able to pay the pensions for which agents previously contributed. If so, contributions are lost and disappear from the economy. The level of the tax rate is decided by majority-voting while the Bismarkian factor is set constitutionally, prior to any vote over the tax rate, so as to maximize a Rawlsian social welfare function..$^{5}$

Without evasion costs, a necessary condition for agents to comply is that the marginal return from public pensions is greater than that of the private annuity market. Interestingly, in that case, choosing how much income to report or choosing the level of the tax rate are perfectly equivalent decisions: if the tax rate increases, agents will perfectly adapt their compliance rate so as to pay the exact same amount of taxes. Hence, at the majority voting equilibrium, there is unanimity in favour of the maximum tax rate. The reasons are twofold. First, because of perfect substitutability between taxation and compliance, the flat (Beveridgian) part of the pension benefit is increasing in the tax rate so that agents with low-income who benefit from that redistribution mechanism want the maximum of that benefit. Second, agents with higher income would like to use the more generous pension system (rather than the private annuity market) to transfer resources to the old age, so that increasing the tax rate is the best way to do so. Finally, at the constitutional stage, the level of the Bismarkian factor is chosen so as to maximise the utility of the poorest agent and it is such that the Beveridgian part of the pension benefit is maximum. It is shown that it is always optimal to have a contributory pension system, as it makes the agents willing to report more income and thus, it increases the resources which can then be distributed through the flat pension benefit. The reason for a contributive pension system is therefore directly related to a tax base increase argument. ${ }^{6}$ In the end, such a pension system maximises the utility of the worst-off.

\footnotetext{
${ }^{4}$ On the relation between ethics, social norms and tax compliance, see Alm et al. (1999), Bobek et al. (2007), Torgler and Schneider (2009) and Wenzel (2004, 2005).

${ }^{5}$ We come back on the justification of the political versus constitutional choice of the policy instruments in Section 3.3 .

${ }^{6}$ This is different from Casamatta et al. (2000a) where the Bismarkian factor is positive to ensure political support. In our model with no evasion cost, the tax rate is independent of the Bismarkian factor.
} 
With a moral cost of evasion, some agents may still report no income. Yet, the introduction of an evasion cost breaks down perfect substitutability between the tax rate and the amount reported to fiscal authorities so that the agent's preferred tax rate now depends on his income. As a consequence, agents at the bottom of the income distribution, may or may not partially comply with the tax system but are in favour of a positive tax rate which is decreasing in their income. In their case, the main reason for a pension system is to benefit from the redistribution operated by the system. To the opposite, agents with higher income, who already fully comply, also want a positive tax rate but it is now increasing in their income. For them, public pensions constitute a more efficient way to transfer resources to the old age (in comparison with private savings whose return is lower). Consequently, we obtain a ends-against-themiddle voting equilibrium, where poor agents form a coalition with high-income agents against middleincome agents, for implementing high tax rates. Finally, even though at the constitutional stage, the objective of the government is to maximize the utility of the least-favoured agents, the Bismarkian factor is in general positive. The reasons are twofold. First, as in the case with no evasion cost, increasing the degree of contributiveness would lead individuals report more honestly their income. This would in turn increase the tax base and the level of the flat pension benefit, which benefits mostly individuals at the bottom of the income distribution. Second, it may be the case that a higher link between contributions and pension benefits increase the support for the pension system. While the second reason was already put forward in political economy models (see Casamatta et al. 2000a, b), the first (obvious) reason is new in the literature.

All in all, independently of whether evasion entails individual costs, giving the possibility to individuals to participate in a contributory pension system would increase compliance and the overall welfare of the society.

Our paper can be related to at least two strands of the literature. First, there is a well-known theoretical literature on tax evasion and how tax compliance varies with income, risk aversion, fiscal instruments, enforcement parameters and social norms (see Allingham and Sandmo, 1972; Yitzhaki, 1974; Cowell and Gordon, 1988; Gordon, 1989; Myles and Naylor, 1996). Also, related to our paper, Baumann et al. (2009) studies contribution evasion in unemployment insurance programs, in a Allingham and Sandmo (1972) type of model. ${ }^{7}$ These papers assume, on purpose, a probability of auditing and a penalty rate in case of detection and, sometimes a cost of non-compliance. To the contrary, we assume away auditing but model instead a moral cost of under-reporting (as in Gordon, 1988, and Traxler, 2009) as well as uncertainty on the provision of the pension benefit. Such a modelling is relevant in particular

\footnotetext{
${ }^{7}$ These authors obtain, like us, that in order to stimulate truthful reporting, insurance programs should be made more contribution-related, even though this is not enough to eliminate evasion. However, we go further by modelling the political equilibrium and the possibility of government default.
} 
for countries where tax enforcement mechanisms are weak and the political risk is high.

Second, our paper can be related to the political economy literature on tax evasion. For instance, Borck $(2004,2009)$ study political economy models in which agents can evade income. ${ }^{8}$ Appart from the questions raised (how stricter enforcement policies may actually increase tax evasion, or how redistribution is impacted by evasion), these papers also differ in several other respects. First, agents are risk neutral so that they either avoid all their income or none of it. This seems a rather restrictive assumption as in general, evasion is not a "all or nothing decision". Second, it assumes that agents get a uniform transfer from their contributions while we model a contribution-related pension system. Third, the only motive for taxation is redistribution and there is no consumption smoothing motive as in our model with pensions. Traxler (2012) also looks at the efficiency effect of tax avoidance when the tax rate is chosen by a majority of taxpayers. His main finding is that the traditional inefficiency carried by majority voting decreases with the extent of tax avoidance. More closely related to our paper, Alm et al. (1999) briefly discuss a political economy model with risk-neutral agents where the presence of a social norm influences agents' tax compliance and thus, their voting behaviour over the increase in tax rate, in the amount of fine and in the probability of detection. ${ }^{9}$ This model is different from ours at least in three dimensions: agents either fully comply or not at all, they receive a lump sum benefit and, individuals' heterogeneity arises from differences in the psychological loss from not complying. Finally, Kopczuk (2001) studies an optimal income taxation scheme when agents have different tax avoidance behaviour, either because of different preferences for avoidance or because of different avoidance cost functions. This is different from our paper first because it is normative and second, because in our model agents only differ with respect to income. In addition, none of of these models consider the possibility of government default as we do.

To the best of our knowledge, our paper is one of the few political economy papers which studies the interaction between tax compliance and the existence of a pension system and how the latter may help reducing inefficiencies related to income under-reporting.

The rest of the paper is organized as follows. The next section presents the model. Section 3 derives a model where agents are free to report their income and where there is no evasion cost. In Section 4 , such costs are introduced. The last section concludes.

\footnotetext{
${ }^{8}$ See also the survey by Borck (2007) on inequality, redistribution and taxation in political economy models.

${ }^{9}$ Their paper is mainly experimental. They show in particular that "when the group rejects any attempt to raise the level of enforcement, compliance always falls, often collapsing to zero". Also cheap talk helps increasing compliance and may change the result of the vote in favour of paying more taxes. See also Besley et al. (2015) which studies the dynamics of tax evasion in presence of interactions between individual and social motives in tax evasion.
} 


\section{The model}

We assume a two-period model, with a mass one of individuals who face uncertain survival and no population growth. Agents have different productivity, $y$ which is continuously distributed over $\left[y_{\min }, y_{\max }\right]$, with median productivity below the average, $y_{m}<\bar{y}$, and density function $f(y)$. In the first period, agents supply inelastically one unit of labour. ${ }^{10}$ They consume, save on private markets and contribute to a public pension system. In the second period, say old-age, they are alive with a probability $0 \leq \pi \leq 1$. If alive, they are retired and consume their private accumulated savings as well as the public pension benefit. There is however a positive probability $\beta \leq 1$ that the government defaults and is not able to provide any benefit. In that case, contributions are lost and we assume that either they disappear from the economy or that they are used for anything else which does not provide direct utility to the agents.

Agents derive utility from consumption in each period. Without loss of generality, we assume that there are no pure time preferences. Individual preferences can be formulated as follows:

$$
E U=u(c)+\pi\left\{(1-\beta) u\left(d_{N}\right)+\beta u\left(d_{D}\right)\right\}
$$

where consumption in the first period is denoted by $c$ while $d_{N}$ (resp. $d_{D}$ ) represents the individual's consumption when the government does not default (resp. defaults) in the second period. Per period utility is such that $u^{\prime}()>0,. u^{\prime \prime}()<$.0 and $u^{\prime}(0) \rightarrow+\infty$. We also make the following assumptions regarding the coefficients of absolute and relative risk aversion, $R_{a}(c)=-u^{\prime \prime}(c) / u^{\prime}(c)$ and $R_{r}(c)=$ $-u^{\prime \prime}(c) c / u^{\prime}(c)$ respectively: $:^{11}$

Assumption 1 The coefficient of absolute risk aversion is decreasing in income: $R_{a}(d) \geq R_{a}(c)$ with $c \geq d$.

Assumption 2 The coefficient of relative risk aversion is increasing in income and smaller than 1: $R_{r}(d) \leq R_{r}(c) \leq 1$ with $c \geq d$

In the first period of their life, agents work and pay a tax at rate $\tau$ on their reported income, $\tilde{y}$ so as to finance the PAYGO public pension program. ${ }^{12}$ For simplicity, we assume that reported income is simply equal to a fraction of the agent's true income, $\tilde{y}=\gamma y$ where $0 \leq \gamma \leq 1$ is the rate of compliance and it

\footnotetext{
${ }^{10}$ Assuming endogenous labour supply would not change our results. The only additional finding is that, surprisingly, taxation would generate no labour supply distortion. The reason is that, in a model where agents can choose how much to comply, the tax rate and the rate of compliance are perfect substitutes when there is no cost of evasion (see Section 3.1 below). Hence, the agent can always perfectly adapt compliance and thus labour supply in response to a variation in the tax rate and attain maximum utility. Computations are available from the authors upon request.

${ }^{11}$ The assumption of decreasing absolute risk aversion is standard in the literature. See also Guiso and Paiella (2008) who find that it is effectively the case. Regarding the estimation of relative risk aversion, Karagyozova and Siegelman (2012) review the empirical literature about it, and find that the assumption that $R_{r}(c) \leq 1$ is reasonable. For instance, Holt and Laury (2002) find that $64 \%$ of respondents has a coefficient comprised between 0.15 and 0.97.

${ }^{12}$ Implicit in our modelling is that the government only imperfectly observes the distribution of incomes in the society and/ or lacks coercive measures to make agents report their income truthfully.
} 
is privately chosen by the agent. ${ }^{13}$ In the second period, individuals consume their savings as well as a pension benefit $P(\tau, \alpha ; y)$ when the government does not default. First and second-period consumptions can thus be expressed as follows:

$$
\begin{aligned}
c & =y-\tau \tilde{y}-s=(1-\tau \gamma) y-s \\
d_{N} & =P(\tau, \alpha ; y)+\frac{\varepsilon}{\pi} s \\
d_{D} & =\frac{\varepsilon}{\pi} s
\end{aligned}
$$

The amount of savings $s$ is assumed to be invested on the private annuity market and its return is $\varepsilon R / \pi$ where, for simplicity, the gross rate of savings return $R$ is set to 1 . The parameter $\varepsilon \in[\pi, 1]$ reflects both the weakness of the annuity market and the inefficiency of the financial institutions for individual savers. $^{14}$

The pension benefit is obtained from balancing the government's budget and is thus equal to:

$$
P(\tau, \alpha ; y)=\frac{\tau}{\pi}(\alpha \tilde{y}+(1-\alpha) E(\tilde{y}))
$$

where $0 \leq \alpha \leq 1$ is the Bismarckian factor. It is constituted of two parts as in Casamatta et al. (2000a). The first Bismarkian part $(\tau \alpha \tilde{y} / \pi)$ is directly linked to the agent's earlier contributions. The second Beveridgian part, $b(\tau, \alpha)=\tau(1-\alpha) E(\tilde{y}) / \pi$ is flat and depends on average reported earnings in the economy,

$$
E(\tilde{y})=E(\gamma(y) y)=\int_{y_{\min }}^{y_{\max }} \gamma(y) y f(y) d y
$$

where $\gamma(y)$ is the compliance rate chosen by an agent with true income $y$. This uniform pension benefit is also called the "redistributive part" of the pension benefit as individuals who reported $\tilde{y}<E(\tilde{y})$ contribute less than what they actually obtain in the second period: $\tau \tilde{y}<\tau(\alpha \tilde{y}+(1-\alpha) E(\tilde{y}))$.

The agent can thus transfer resources to the old age by contributing to the pension system and / or investing in a private annuity market, and the marginal return from private annuities is equal to $\varepsilon / \pi$ while that of contributing to the pension system is $\alpha / \pi$. At this stage, we make no specific assumption regarding the levels of $\alpha$ and $\varepsilon$.

The timing of the model is the following. First, the level of the Bismarkian factor, $\alpha$ is set at the constitutional level so as to maximize the utility of the worst-off agent. ${ }^{15}$ Agents then vote over the level of the tax rate, $\tau$ that will finance the pension system. Finally, given the tax rate chosen at the majority voting equilibrium $\tau^{V}$, they make private decisions over compliance and savings, $(\gamma, s)$. As usual in this type of problem, we proceed backward.

\footnotetext{
${ }^{13}$ Contrary to Borck (2009) and Alm et al. (1999), in our model, agents are free to evade all their income, none of it or only a fraction.

${ }^{14}$ If there was no private annuity market but if the individual could save at the current interest rate (here assumed to be zero), $\varepsilon$ would simply be equal to $\pi$ and the return from saving would be 1 .

${ }^{15}$ We come back at the beginning of Section 3.3 as of why we use that type of modelling of the government's decision.
} 


\section{A compliance-choice model with no cost of evasion}

To start with, we assume in that section, that not complying with the fiscal law does not entail any moral cost as well as no risk of punishment in case of non compliance. We relax the first assumption in the next section.

\subsection{Individual decisions}

For given pension parameters $(\tau, \alpha)$, the problem of an agent with income $y$ consists in solving ${ }^{16}$

$$
\max _{s, \gamma} E U(\gamma, s ; y)=u((1-\gamma \tau) y-s)+\pi\left\{(1-\beta) u\left(\frac{\tau}{\pi}(\alpha \gamma y+(1-\alpha) E(\tilde{y}))+\frac{\varepsilon}{\pi} s\right)+\beta u\left(\frac{\varepsilon}{\pi} s\right)\right\}
$$

First order conditions with respect to $(\gamma, s)$ are:

$$
\begin{aligned}
\frac{\partial E U}{\partial s} & =-u^{\prime}(c)+\varepsilon\left\{(1-\beta) u^{\prime}\left(d_{N}\right)+\beta u^{\prime}\left(d_{D}\right)\right\} \leq 0 \\
\frac{\partial E U}{\partial \gamma} & =\tau y\left[-u^{\prime}(c)+\alpha(1-\beta) u^{\prime}\left(d_{N}\right)\right] \leq 0
\end{aligned}
$$

Using (2), it is clear that $s^{*}(\tau, \alpha ; y)>0$ under the assumption that $u^{\prime}(0) \rightarrow+\infty$. Private savings serve here as an insurance mechanism against government default. The FOC with respect to $\gamma$ can be rewritten as follows:

$$
\frac{\partial E U}{\partial \gamma}=\tau y\left[-\varepsilon \beta u^{\prime}\left(d_{D}\right)+(1-\beta)(\alpha-\varepsilon) u^{\prime}\left(d_{N}\right)\right] \leq 0
$$

where we substituted for (2). Evaluating it in $\gamma=0$, it is clear that a sufficient condition for $\gamma=0$ is $\alpha \leq \varepsilon$. Indeed, if investing in public pensions is both risky and gives a lower return than private savings, the agent should better invest in the private saving market only. For instance, if $\alpha=\varepsilon$, increasing compliance entails a marginal utility cost in the first period which is identical to that of private savings, but no higher return in the second period so that agents prefer private savings whose return is certain and $\gamma^{*}(\tau, \varepsilon ; y)=0 \forall y$. Hence, $\alpha$ needs to be sufficiently large to compensate for the uncertainty of government payments and provide incentives to comply.

For this reason, from now on, we focus on the case where $\alpha>\varepsilon$ and we obtain the following ranking of consumptions: $c>d_{N}>d_{D} \cdot{ }^{17}$ Using the Cramer's rule and Assumption 2, we find that both compliance and saving are increasing in income. Indeed, as the agent becomes richer, both the (first-period) marginal cost of transferring resources to the old age and its (second-period) marginal benefit decrease; Assumption

\footnotetext{
${ }^{16}$ Second-order conditions are satisfied.

${ }^{17}$ We show in Section 3.3 that the case where $\varepsilon>\alpha^{R}\left(\alpha^{R}\right.$ being the constitutional level of $\alpha$ chosen by a Rawlsian government) never happens.
} 
2 guarantees however that the marginal cost decreases more rapidly than the marginal benefit so that a richer agent is willing to transfer more resources to the second period. ${ }^{18}$

The variation of $\gamma^{*}(\tau, \alpha ; y)$ with $y$ therefore enables us to define two income thresholds, one below which agents do not comply, and one above which they fully comply. First, the income threshold below which agents choose not to report any income, $\hat{y}(\tau, \alpha)$ is defined by

$$
u^{\prime}(\hat{y}-\hat{s})=\alpha(1-\beta) u^{\prime}\left(\frac{\tau}{\pi}(1-\alpha) E(\tilde{y})+\frac{\varepsilon}{\pi} \hat{s}\right)
$$

with $\hat{s}=s^{*}(\tau, \alpha ; \hat{y}) \cdot{ }^{19}$ Hence, agents with $y \leq \hat{y}(\tau, \alpha)$ choose $\gamma^{*}=0$ while those with $y>\hat{y}(\tau, \alpha)$ choose a strictly positive $\gamma^{*}$ satisfying (3).

Second, the income threshold, $\breve{y}(\tau, \alpha)$ above which agents fully comply with the fiscal system is defined by

$$
u^{\prime}(\breve{y}(1-\tau)-\breve{s})=(1-\beta) \alpha u^{\prime}\left(\frac{\tau}{\pi}(\alpha \breve{y}+(1-\alpha) E(\tilde{y}))+\frac{\varepsilon}{\pi} \breve{s}\right)
$$

with $\breve{s}=s^{*}(\tau, \alpha ; \breve{y})$. Agents with $y \geq \breve{y}(\tau, \alpha)$ report all their income, $\gamma^{*}=1$ and for them, marginal benefit from compliance is greater than its marginal cost, $\alpha(1-\beta) u^{\prime}\left(d_{N}\right) \geq u^{\prime}(c)$.

Hence, for given pension parameters $(\tau, \alpha)$, agents comply $\left(\gamma^{*} \geq 0\right)$ only if they expect a sufficiently high marginal utility return from public pensions which depends on their income level. If their income is below $\hat{y}(\tau, \alpha)$, the marginal utility from first-period consumption, equivalently the marginal utility cost of reporting income, is higher than the marginal utility obtained from previous contributions in the second period so that they choose $\gamma^{*}(\tau, \alpha ; y)=0$. On the contrary, if $y>\hat{y}(\tau, \alpha)$, the marginal utility obtained from previous contributions is always higher than the marginal cost of reporting income and $\gamma^{*}(\tau, \alpha ; y)>0$. If, their income is sufficiently important, above $\breve{y}(\tau, \alpha)$, they would even want to report more than their full income so as to transfer more resources (at a higher return $\alpha$ compared to private savings) toward the second period.

We summarize the findings regarding individuals decisions in the following proposition:

Proposition 3 Assume a population of agents with income $y \in\left[y_{\min }, y_{\max }\right]$ who have the possibility to save on a private annuity market and to choose how much income to report so as to finance a risky public pension system. In the absence of evasion costs,

- If $\alpha \leq \varepsilon$, every agents prefer private savings over the public pension system, so that $\gamma^{*}(\tau, \alpha ; y)=0$ and $s^{*}(\tau, \alpha ; y)>0 \forall y$.

\footnotetext{
${ }^{18}$ Allingham and Sandmo (1972) obtain a similar result that the fraction of reported income increases with income under increasing relative risk-aversion.

${ }^{19}$ We abbreviate $\gamma^{*}(\tau, \alpha ; y)$ and $s^{*}(\tau, \alpha ; y)$ by $\gamma^{*}$ and $s^{*}$, and do this also for other variables in the manuscript when these shortened notations are non ambiguous.
} 
- If $\alpha>\varepsilon$, agents with income $y \leq \hat{y}(\tau, \alpha)$ do not report any income and receive $b(\tau, \alpha)$ at retirement. Agents with income $y>\hat{y}(\tau, \alpha)$ report a fraction $0<\gamma^{*}(\tau, \alpha ; y) \leq 1$ and receive $P(\tau, \alpha ; y)$ at retirement. In addition, $s^{*}(\tau, \alpha ; y)>0$ for all agents.

Let us now show that, for agents with income $\hat{y}(\tau, \alpha)<y<\breve{y}(\tau, \alpha)$, choosing $\gamma$ for a given $\tau$ is equivalent to letting agents choose their preferred effective tax rate level $t \in[0,1]$ defined as $t=\gamma \tau$. In order to understand this, we make a change of variable in the agent's utility function (1) so that it is now written as:

$$
E U(t, s ; y)=u((1-t) y-s)+\pi\left\{(1-\beta) u\left(\frac{1}{\pi}(\alpha t y+(1-\alpha) E(t y))+\frac{\varepsilon}{\pi} s\right)+\beta u\left(\frac{\varepsilon}{\pi} s\right)\right\}
$$

where $\tau$ disappears from the above expression. Maximizing $E U(t, s ; y)$ with respect to $t$ yields the following first-order condition: ${ }^{20}$

$$
\frac{\partial E U(t, s ; y)}{\partial t}=y\left[-u^{\prime}(c)+\alpha(1-\beta) u^{\prime}\left(d_{N}\right)\right] \leq 0
$$

This optimality condition, which gives the optimal level $t^{*}(\alpha ; y)$, is the same as the optimality condition for $\gamma^{*}(\tau, \alpha ; y)$ and is independent of $\tau$. Hence, the problem where an agent chooses his rate of compliance $\gamma^{*}$ for a given $\tau$ is exactly equivalent to a problem where the agent chooses directly his preferred rate of contribution $t^{*}$, not having any choice on how much income to report.

As it is clear from (7), $t^{*}(\alpha ; y)$ is independent of $\tau$ for agents with income $\hat{y}(\tau, \alpha)<y<\breve{y}(\tau, \alpha)$. This means that for any tax rate $\tau>0$, these agents always pay their preferred amount of effective taxation $t^{*}(\alpha ; y)$ by adapting exactly how much they report, i.e. $\gamma^{*}(\tau, \alpha ; y)$, to a variation in the level of the tax rate. As a consequence, the flat pension benefit, $b(\tau, \alpha)=(1-\alpha) \tau E(\tilde{y}) / \pi$ is increasing in $\tau{ }^{21}$

Also, since $t^{*}(\alpha ; y)$ is independent of $\tau$, we can show that $d \gamma^{*}(\tau, \alpha ; y) / d \tau<0 .{ }^{22}$ There is not a clear consensus in the literature regarding the effect of increasing the tax rate on compliance. It depends on the design of the fiscal system and specifically, on whether penalties are applied on the income evaded or on taxation evaded (see Yitzhaki, 1974 and Christiansen, 1980). Here, the reason is different: it is simply that, in the absence of compliance costs, $\gamma$ and $\tau$ are perfect substitutes.

We now turn to studying individual preferences for the tax rate as well as the majority-voting equilibrium.

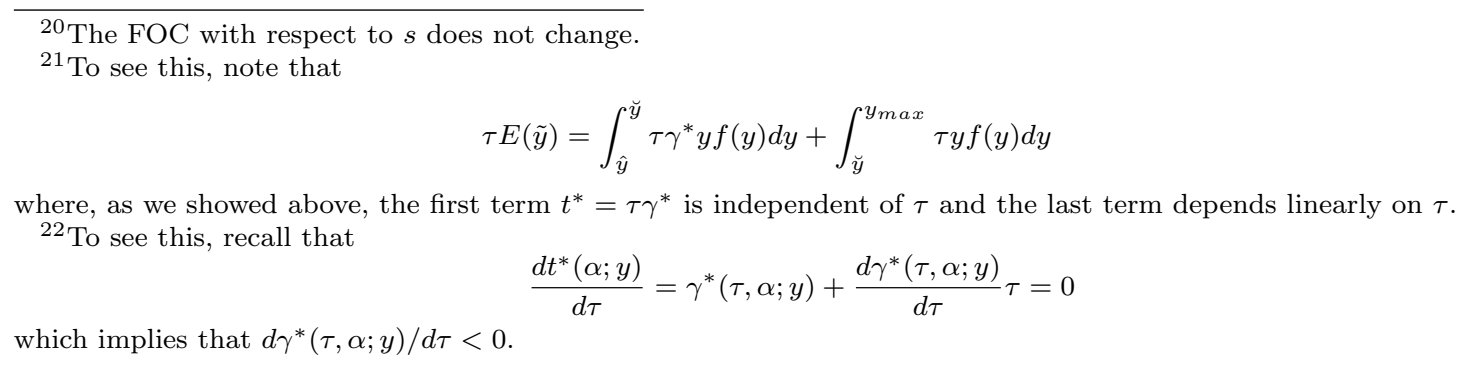




\subsection{Preferences over the tax rate and the majority-voting equilibrium}

The indirect utility function of an agent with income $y$ takes the following form:

$$
\begin{aligned}
V(\tau, \alpha ; y) & =u\left(\left(1-\gamma^{*}(\tau, \alpha ; y) \tau\right) y-s^{*}(\tau, \alpha ; y)\right) \\
& +\pi\left\{(1-\beta) u\left(\frac{\tau}{\pi}\left(\alpha \gamma^{*}(\tau, \alpha ; y) y+(1-\alpha) E(\tilde{y})\right)+\frac{\varepsilon}{\pi} s^{*}(\tau, \alpha ; y)\right)+\beta u\left(\frac{\varepsilon}{\pi} s^{*}(\tau, \alpha ; y)\right)\right\}
\end{aligned}
$$

where $0 \leq \gamma^{*}(\tau, \alpha ; y) \leq 1$ and $s^{*}(\tau, \alpha ; y)>0$ when $\alpha>\varepsilon$. The following first order condition with respect to $\tau$,

$$
\frac{\partial V(\tau, \alpha ; y)}{\partial \tau}=\gamma^{*}(\tau, \alpha ; y) y\left[\alpha(1-\beta) u^{\prime}\left(d_{N}\right)-u^{\prime}(c)\right]+\pi u^{\prime}\left(d_{N}\right)(1-\beta) \frac{d b(\tau, \alpha)}{d \tau}
$$

is always positive. ${ }^{23}$ Indeed, the second term is always positive as we showed before. The first term is nil for every agent with $y \leq \hat{y}(\tau, \alpha)$ since for them, $\gamma^{*}(\tau, \alpha ; y)=0$. This is also the case for those with $\hat{y}(\tau, \alpha)<y \leq \breve{y}(\tau, \alpha)$ since for them, $\gamma^{*}(\tau, \alpha ; y)>0$ satisfies $(3)$. For agents with $y>\breve{y}(\tau, \alpha)$, the first term is also strictly positive since for them $\gamma^{*}=1$ and $\alpha(1-\beta) u^{\prime}\left(d_{N}\right)-u^{\prime}(c)>0$.

The majority-voting equilibrium under $\alpha>\varepsilon$ is then quite straightforward. There is unanimity in favour of the maximum tax rate possible, $\tau^{V} \rightarrow 1 .^{24}$ This is so because agents with $y \leq \breve{y}(\tau, \alpha)$ want to obtain the maximum of the uniform pension benefit $b(\tau, \alpha)$ (either because they do not comply at all or because they can perfectly adapt their compliance to the tax rate) while agents with $y>\breve{y}(\tau, \alpha)$ would like, in addition, to transfer more resources toward old age, through the more generous public pension system (if they could, they would report even more than their full income). Once the majority voting tax rate is implemented, agents choose their rate of compliance. Those with $y \leq \hat{y}(\tau, \alpha)$ report nothing, $\gamma^{*}\left(\tau^{V}, \alpha ; y\right)=t^{*}\left(\tau^{V}, \alpha ; y\right)=0$ and they obtain the Beveridgian part of the pension benefit in the second period. Richer individuals, with $\hat{y}(\tau, \alpha)<y \leq \breve{y}(\tau, \alpha)$, choose a positive level of compliance, $0 \leq \gamma^{*}\left(\tau^{V}, \alpha ; y\right) \leq 1$ or equivalently $t^{*}\left(\tau^{V}, \alpha ; y\right)=\tau^{V} \gamma^{*}\left(\tau^{V}, \alpha ; y\right)>0$ which increases in income. Finally, agents with $y>\breve{y}(\tau, \alpha)$ report their full income and $t^{*}\left(\tau^{V}, \alpha ; y\right)=\tau^{V}>0$. Compliance to the tax system of middle- and high-income agents will benefit the entire population, even those agents who did not report any income, through the distribution of the lump sum benefit $b(\tau, \alpha)$.

Note finally that, for a given $\alpha$, agents with $y \leq \breve{y}(\tau, \alpha)$, always obtain, at the majority-voting equilibrium, maximum utility, which corresponds to the level obtained at their preferred allocation $\left(\gamma^{*}\left(\tau^{*}(\alpha ; y), \alpha ; y\right), s^{*}\left(\tau^{*}(\alpha ; y), \alpha ; y\right), \tau^{*}(\alpha ; y)\right) .{ }^{25}$ To the contrary, agents with $y>\breve{y}(\tau, \alpha)$ obtain a lower level of utility since the faction of income they can report is bounded at one.

\footnotetext{
${ }^{23}$ We make the assumption that second-order conditions are satisfied.

${ }^{24}$ This is the case here because labour is inelastic.

${ }^{25}$ This is due to the fact that they can perfectly adapt compliance so as to obtain their most-preferred level of effective tax rate $t^{*}(\alpha ; y)$, independently of $\tau^{V}$.
} 
Our results are summarized in the following proposition.

Proposition 4 When $\alpha>\varepsilon$ and in the absence of evasion costs,

- Every agent is in favour of the maximum tax rate level.

- At the majority voting equilibrium, there is unanimity in favour of $\tau^{V} \rightarrow 1$.

- At the majority voting equilibrium, agents with $y \leq \breve{y}(\tau, \alpha)$ obtain maximum utility.

\subsection{Constitutional choice of the level of the Bismarkian factor}

We assume that $\alpha$ is chosen at an "initial" constitutional stage where a Rawlsian social planner chooses to maximize the utility of the agent with income $y_{\min }$. This modelling could be questioned in several respects. First, one could have assumed that $\alpha$ is chosen by majority-voting. As it becomes clear below, if the median voter has a low income, below $\hat{y}(\tau, \alpha)$, it does not change our results. ${ }^{26}$ One could also argue that the redistributivity of the pension system is a characteristic which results from countries specific traditions and culture regarding the role of public institutions. For this reason, it seems rather difficult to overturn it in the short run, contrary to the contribution rate which is more subject to fluctuations across time and to political cycles. ${ }^{27}$ Second, one could have chosen a different objective function for the social planner such as for instance, a Utilitarian objective. We derive only the Rawlsian solution which is a special case of the Utilitarian social welfare function where all the weight is put on one individual, i.e. the one with smallest income. In this special case, the redistributive motive is maximum and, in a sense, our results are biased toward the lowest level of $\alpha$, i.e. the highest level of redistribution.

Let us now determine the level of $\alpha$ when $\alpha>\varepsilon$ and check ex post that it is verified. Using our previous results on individual optimal decisions (Section 3.1) and the level of the majority voting tax rate (Section 3.2), the problem of the Rawlsian social planner consists then in solving:

$$
\begin{aligned}
\max _{\alpha} V\left(\tau^{V}, \alpha ; y_{\min }\right) & =u\left(y_{\min }-s^{*}\left(\tau^{V}, \alpha, y_{\min }\right)\right) \\
& +\pi\left\{(1-\beta) u\left(b\left(\tau^{V}, \alpha\right)+\frac{\varepsilon}{\pi} s^{*}\left(\tau^{V}, \alpha, y_{\min }\right)\right)+\beta u\left(\frac{\varepsilon}{\pi} s^{*}\left(\tau^{V}, \alpha, y_{\min }\right)\right)\right\}
\end{aligned}
$$

with $b\left(\tau^{V}, \alpha\right)=\tau^{V}(1-\alpha) E(\tilde{y}) / \pi, \tau^{V}$ independent of $\alpha$ and $E(\tilde{y})=E\left(\gamma^{*}\left(\tau^{V}, \alpha, y\right) y\right)$. Since, by definition $y_{\text {min }}<\hat{y}\left(\tau^{V}, \alpha\right)$, the agent with minimum income does not comply and thus, receives at retirement only the flat pension benefit, $b\left(\tau^{V}, \alpha\right)$. Differentiating this expression with respect to $\alpha$ and using the envelop theorem for the derivation of $s^{*}\left(\tau^{V}, \alpha, y_{\min }\right)$, we obtain:

$$
\frac{\partial V\left(\tau^{V}, \alpha ; y_{\min }\right)}{\partial \alpha}=(1-\beta) u^{\prime}\left(d_{N}\right) \tau^{V}\left[(1-\alpha) \frac{d E(\tilde{y})}{d \alpha}-E(\tilde{y})\right]
$$

\footnotetext{
${ }^{26}$ In this baseline model, choosing both $\tau$ and $\alpha$ by majority voting is simple, in particular because $\tau^{V} \rightarrow 1$. Yet, in a more complicated two-dimensional choice setting with compliance costs, a Condorcet winner may not exist.

${ }^{27}$ For instance, Germany and France are traditionally more Bismarckian while UK is traditionally more Beveridgean. For a discussion on the constitutional versus political choices of $(\alpha, \tau)$, see Casamatta et al. (2000a).
} 
so that maximizing the utility of the worst-off is equivalent to maximizing the flat pension benefit. Evaluating the above expression in $\alpha=\varepsilon$, one can show that $\partial V\left(\tau^{V}, \alpha ; y_{\min }\right) /\left.\partial \alpha\right|_{\alpha=\varepsilon}>0$. To do so, we show in Appendix 6.1 that $d E(\tilde{y}) /\left.d \alpha\right|_{\alpha=\varepsilon}>0$ while in $\alpha=\varepsilon, \gamma^{*}=0 \forall y$ so that $E(\tilde{y})=0$. It is also straightforward to see that $\partial V\left(\alpha ; y_{\min }\right) /\left.\partial \alpha\right|_{\alpha=1}<0$. Hence, the optimal $\alpha^{R}$ is effectively above $\varepsilon$ and maximises $b\left(\tau^{V}, \alpha\right)$ such that:

$$
\left(1-\alpha^{R}\right) \frac{d E(\tilde{y})}{d \alpha}=E(\tilde{y})
$$

Therefore, the only reason here for a positive $\alpha$ is related to its indirect effect on $b(\tau, \alpha)$ through $E(\tilde{y})$. A higher $\alpha$ increases the tax base $E(\tilde{y})$ through higher compliance and, thus the flat pension benefit which benefits primarily the least-favoured. This effect would have been absent if full compliance were unavoidable (i.e. $\gamma=1 \forall y$ ), and is new with regards to the existing literature on the political economy of pension systems, which did not consider the possibility to evade contributions.

Note in addition that, contrary to Casamatta et al. (2000a), the effect of $\alpha$ on the political support for $\tau^{V}$ is absent here. This is a direct consequence of the perfect substitutability between $\tau$ and $\gamma$, which in turn, implies that agents are in favour of $\tau^{V}$ maximum.

A public pension system with parameters $\left(\tau^{V}, \alpha^{R}\right)$ will therefore provide maximum utility to agents with the lowest income since 1) at the majority-voting equilibrium, they obtain maximum utility for a given $\alpha$ and 2) $\alpha$ is here chosen so as to maximise the utility of the worst-off.

\section{Introducing a cost of evasion}

\subsection{Individual decisions}

We now depart from our original model to assume that not complying with the tax system entails a moral or reputation cost to the agent when he deviates from the social norm of reporting honestly income (See Gordon,1989; Traxler, 2010). ${ }^{28}$ Following Gordon (1989), we assume from now on that an agent with income $y$ faces a linear utility cost of evasion of the following form:

$$
C(\gamma, \tau ; y)=\frac{\chi}{\beta} \tau y(1-\gamma)
$$

where $\chi \geq 0$ is a parameter representing the intensity of the moral cost supported by the agent and, $\tau y(1-\gamma)$ are the evaded payments resulting from non compliance, as in Yitzhaki (1974). This cost is certain and supported in the first period, at the time the agent makes the decision to evade income, and

\footnotetext{
${ }^{28}$ Alternatively, we could have assumed that the evasion cost is monetary, when the agent has to pay lawyers or financial experts to avoid taxation. It can also take time, which the agent cannot use for remunerated activities. In these situations, we would have included this cost directly into the agent's first period utility of consumption. In a previous version, we try this modelling but it proves to be more difficult to handle mathematically, in particular for the voting equilibrium, with no additional results.
} 
it is increasing in evaded payments. ${ }^{29}$ We also assume that the cost depends negatively on the probability of default of the pension system so as to account for the idea that the individual would less reluctant to avoid taxation if he believes the government could default with a higher probability.

In the following, we assume that $\alpha>\varepsilon$ so as to make direct comparisons with the baseline model with no evasion cost (Section 3). ${ }^{30}$ For given pension parameters $(\tau, \alpha)$, problem (1) of an agent with income $y$ is now modified, so as to account for the cost of not complying with the tax system, as follows:

$$
\max _{s, \gamma} u(y(1-\gamma \tau)-s)+\pi\left\{(1-\beta) u\left(\frac{\tau}{\pi}[\alpha \gamma y+(1-\alpha) E(\tilde{y})]+\frac{\varepsilon s}{\pi}\right)+\beta u\left(\frac{\varepsilon s}{\pi}\right)\right\}-\frac{\chi}{\beta} \tau y(1-\gamma)
$$

If $\chi=0$, there is no cost of compliance and we are back to the original model. First order conditions with respect to $s$ and $\gamma$ are:

$$
\begin{aligned}
\frac{\partial E U}{\partial s} & =-u^{\prime}(c)+\varepsilon\left\{(1-\beta) u^{\prime}\left(d_{N}\right)+\beta u^{\prime}\left(d_{D}\right)\right\}=0 \\
\frac{\partial E U}{\partial \gamma} & =y \tau\left[-u^{\prime}(c)+\alpha(1-\beta) u^{\prime}\left(d_{N}\right)+\frac{\chi}{\beta}\right] \leq 0
\end{aligned}
$$

The first condition is identical to our original model so that $s^{*}(\tau, \alpha ; y)>0$. Again, private savings are used as an insurance mechanism in case of government default in the second period. The second condition which defines $\gamma^{*}(\tau, \alpha ; y)$ however differs from our original model by the term $\chi / \beta$ which accounts for the marginal utility cost of not complying with the tax system. In other words, there is now an additional marginal benefit to compliance, which corresponds to a decrease in marginal (moral) utility cost from not complying with the tax law.

Since the above two FOCs are similar to the ones of the baseline model (up to the constant term in the FOC for $\gamma)$, the comparative statics of $s^{*}(\tau, \alpha ; y)>0$ and $0<\gamma^{*}(\tau, \alpha ; y) \leq 1$ are also similar. Indeed, using the Cramer's rule and under $\mathrm{A} 1, d s^{*}(\tau, \alpha ; y) / d y>0$ so that high-income agents save more on private markets than low-income ones. Similarly, $d \gamma^{*}(\tau, \alpha ; y) / d y>0$ so that high-income agents comply more with the fiscal system than low-income ones.

We now define the income threshold below which agents report nothing, $\gamma^{*}=0$ by evaluating (14) at $\gamma=0$. This threshold income level, $\hat{y}_{E C}(\tau, \alpha)$ is now implicitly defined by:

$$
u^{\prime}\left(\hat{y}_{E C}-\hat{s}_{E C}\right)=\alpha(1-\beta) u^{\prime}\left(b(\tau, \alpha)+\frac{\varepsilon}{\pi} \hat{s}_{E C}\right)+\frac{\chi}{\beta}
$$

with $\hat{s}_{E C}=s\left(\tau, \alpha ; \hat{y}_{E C}\right)$. Therefore, for agents with $y \leq \hat{y}_{E C}(\tau, \alpha)$, marginal cost of reporting income is higher than its marginal benefit: $u^{\prime}(c)>\alpha(1-\beta) u^{\prime}\left(d_{N}\right)+\chi / \beta$ and $\gamma^{*}=0$. Comparing this condition

\footnotetext{
${ }^{29}$ This is different from Allingham and Sandmo (1972), Yitzhaki (1974), Borck (2004, 2009) and Traxler (2012) where agents face a probability of being audited and of having to pay expensive fines. Here, the moral cost of non compliance is certain, but uncertainty resides in whether the government is going to default or not.

${ }^{30}$ Note however that this is not a necessary condition for $\gamma>0$. Indeed, depending on the level of $\chi$, one could have $\gamma>0$ even though $\varepsilon>\alpha$.
} 
with that of the baseline model, one finds that the introduction of a moral cost of evasion leads to a lower threshold level of productivity $\left(\hat{y}_{E C}\right)$ for which the agent does not report any income than when there was no cost of evasion $(\hat{y})$.

In the same way, we define $\breve{y}_{E C}(\tau, \alpha)$, the income threshold above which agents report their full income and $\gamma^{*}(\tau, \alpha ; y)=1$. It is defined by (14) evaluated in $\gamma=1$ such that

$$
u^{\prime}\left(\breve{y}_{E C}(1-\tau)-\breve{s}_{E C}\right)=(1-\beta) \alpha u^{\prime}\left(\frac{\tau}{\pi}\left(\alpha \breve{y}_{E C}+(1-\alpha) E(\tilde{y})\right)+\frac{\varepsilon}{\pi} \breve{s}_{E C}\right)+\frac{\chi}{\beta}
$$

with $\breve{s}_{E C}=s\left(\tau, \alpha ; \breve{y}_{E C}\right)$. For the same reason as above, the introduction of a cost of evasion increases marginal benefit from complying with the law by a factor $\chi / \beta$ so that $\breve{y}_{E C}<\breve{y}$. As before, agents with $y>\breve{y}_{E C}(\tau, \alpha)$ would like to report even more than their full income, since they would like to use the public pension system to transfer more resources to the old age at a higher return than with private savings. In their case, the constraint that $\gamma^{*}$ cannot be above one implies that $\alpha(1-\beta) u^{\prime}\left(d_{N}\right)+\chi / \beta>u^{\prime}(c)$.

Individuals decisions are summarized in the following proposition.

Proposition 5 Assume a population of agents with income $y \in\left[y_{\min }, y_{\max }\right]$ who have the possibility to save on a private annuity market and to choose the fraction of income they wish to report so as to finance a risky public pension system. Assume also that evasion generates a moral cost.

- Every agent chooses to save on private markets: $s^{*}(\tau, \alpha ; y)>0 \forall y$ and it is increasing in $y$.

- Agents with income $y \leq \hat{y}_{E C}(\tau, \alpha)$ do not report any income: $\gamma^{*}(\tau, \alpha ; y)=0$.

- Agents with income $\hat{y}_{E C}(\tau, \alpha)<y \leq \breve{y}_{E C}(\tau, \alpha)$ report a positive fraction of income, $0<\gamma^{*}(\tau, \alpha ; y) \leq$ 1, which satisfies (14)and is increasing in $y$.

- Agents with $y>\breve{y}_{E C}(\tau, \alpha)$ report all their income, $\gamma^{*}(\tau, \alpha ; y)=1$.

One important difference with respect to the previous section is that the introduction of a moral cost of evasion breaks up the perfect substitutability between compliance (through the choice of $\gamma$ ) and the tax rate from the point of view of the individual. To see this, let us rewrite the expected utility function of agents with income $\hat{y}_{E C}(\tau, \alpha)<y<\breve{y}_{E C}(\tau, \alpha)$ as a function of the effective tax rate $t=\gamma \tau$ :

$$
E U(t, s ; y)=u((1-t) y-s)+\pi\left\{(1-\beta) u\left(\frac{1}{\pi}(\alpha t y+(1-\alpha) E(t y))+\frac{\varepsilon}{\pi} s\right)+\beta u\left(\frac{\varepsilon}{\pi} s\right)\right\}-\frac{\chi y(\tau-t)}{\beta}
$$

As it is clear from above, even after the change in variable, the tax rate $\tau$ appears explicitly in the expected utility of the agent, through the cost of compliance so that the agent will not be able anymore to perfectly adapt his level of $\gamma$ to a variation of $\tau$ so as to keep his expected utility constant. This point 
will prove to be crucial for determining individuals preference for the tax rate and the voting equilibrium in the next section.

We now turn to studying individual preferences for the tax rate as well as the majority-voting equilibrium.

\subsection{Preference for the tax rate and the majority-voting equilibrium.}

\subsubsection{Individuals' preferred tax rate}

The indirect utility function of an agent with income $y$ writes:

$$
\begin{aligned}
V(\tau, \alpha ; y) & =u\left(y\left(1-\gamma^{*}(\tau, \alpha ; y) \tau\right)-s^{*}(\tau, \alpha ; y)\right) \\
& +\pi\left\{(1-\beta) u\left(\frac{\tau}{\pi}\left[\alpha \gamma^{*}(\tau, \alpha ; y) y+(1-\alpha) E(\tilde{y})\right]+\frac{\varepsilon s^{*}(\tau, \alpha ; y)}{\pi}\right)+\beta u\left(\frac{\varepsilon s^{*}(\tau, \alpha ; y)}{\pi}\right)\right\}-\frac{\chi \tau y\left(1-\gamma^{*}(\tau, \alpha ; y)\right)}{\beta}
\end{aligned}
$$

where $0 \leq \gamma^{*}(\tau, \alpha ; y) \leq 1 \forall y$ and $s^{*}(\tau, \alpha ; y)>0$ have been characterized in the previous section.

In the following, we derive tax rate preferences of individuals depending on their income level. Differentiating $V(\tau, \alpha ; y)$ with respect to $\tau$, we obtain ${ }^{31}$

$$
\begin{aligned}
\frac{\partial V(\tau, \alpha ; y)}{\partial \tau} & =-u^{\prime}(c) y \gamma^{*}(\tau, \alpha ; y) \\
& +\pi(1-\beta) u^{\prime}\left(d_{N}\right)\left[\frac{\alpha \gamma^{*}(\tau, \alpha ; y) y}{\pi}+\frac{d b(\tau, \alpha)}{d \tau}\right]-\frac{\chi y\left(1-\gamma^{*}(\tau, \alpha ; y)\right)}{\beta} \leq 0 .
\end{aligned}
$$

where we assume that $d b(\tau, \alpha) / d \tau>0$, i.e. we are on the increasing part of the Laffer curve. This expression differs from our baseline equation (8) by the last term in the above expression which represents the variation of the moral cost of evading income with respect to the tax rate. This term therefore decreases the preference for a positive tax rate, everything else being equal, since the moral cost of evasion depends on evaded payments (and not on evaded income) and increases directly with the level of taxation.

Rearranging terms in the above expression such that,

$$
\frac{\partial V(\tau, \alpha ; y)}{\partial \tau}=y \gamma^{*}(\tau, \alpha ; y)\left[-u^{\prime}(c)+(1-\beta) \alpha u^{\prime}\left(d_{N}\right)+\frac{\chi}{\beta}\right]+\pi(1-\beta) u^{\prime}\left(d_{N}\right) \frac{d b(\tau, \alpha)}{d \tau}-\frac{\chi y}{\beta} \leq 0,
$$

we now find individuals preferred tax rates depending on whether their income level is above or below $\hat{y}_{E C}(\tau, \alpha)$ and $\breve{y}_{E C}(\tau, \alpha)$. For agents with $y \leq \hat{y}_{E C}(\tau, \alpha)$ who only save on private markets and have $\gamma^{*}(\tau, \alpha)=0$, the above FOC simplifies to:

$$
\frac{\partial V(\tau, \alpha ; y)}{\partial \tau}=\pi(1-\beta) u^{\prime}\left(d_{N}\right) \frac{d b(\tau, \alpha)}{d \tau}-\frac{\chi y}{\beta} \leq 0
$$

\footnotetext{
${ }^{31}$ We use the envelop theorem for $s^{*}(\tau, \alpha ; y)$ and $\gamma^{*}(\tau, \alpha ; y)$ when the solution is interior. When $\gamma^{*}(\tau, \alpha ; y)=0$ or 1 , the envelop theorem does not apply, but obviously, $\gamma^{*}(\tau, \alpha ; y)$ does not vary with $\tau$ so that the FOC with respect to $\tau$ is identical in all cases. We assume that the second-order condition holds.
} 
where $d_{N}=b(\tau, \alpha)+\varepsilon s^{*} / \pi$ since they do not receive the contributive part of the pension benefit. The first term represents the marginal utility obtained from second-period consumption while the second term represents the marginal moral cost following an increase in taxation when the agent evades all his income. Note that if $\chi=0$, the above expression is always positive so that agents within this income interval prefer the maximum tax rate (i.e. the one that maximises $b(\tau, \alpha))$ since in that case there are only benefits to increasing taxation. To the opposite, for a given intensity of the cost of compliance $\chi>0$, individuals' preferred tax rates depend on their income level. To see this, we use the implicit function theorem on (18) and recalling that $d s^{*}(\tau, \alpha ; y) / d y>0 \forall y$, we find that $d \tau^{*}(\alpha ; y) / d y<0$ for $y \in\left[y_{\min }, \hat{y}_{E C}(\tau, \alpha)\right]$. Hence, agents with smaller income prefer a higher tax rate than those with higher income. Agents at the very bottom of the distribution prefer a positive tax rate; in their case, the marginal utility from second-period consumption dominates the marginal cost of taxation (since their income is very low). But as income increases within the interval $y \in\left[y_{\min }, \hat{y}_{E C}(\tau, \alpha)\right]$, marginal utility from second period consumption $d_{N}$ decreases (saving increase) while the marginal moral cost of evading increases.

Let us now derive the preferred tax rate of agents with income $y \in\left[\hat{y}_{E C}(\tau, \alpha), \breve{y}_{E C}(\tau, \alpha)\right]$ for whom $0<\gamma^{*} \leq 1$. Using the Envelop Theorem for $\gamma^{*}(\alpha, \tau)$ in the FOC for $\tau$ (equation 17), we obtain the same expression as (18), except that $\gamma^{*}(\alpha, \tau)>0$ for these agents so that second-period consumption $d_{N}$ now includes the contributive part of the pension benefit. ${ }^{32}$ Using the implicit function theorem on (18), we again obtain that $\tau^{*}(\alpha ; y)$ is decreasing in $y$ within the interval $y \in\left[\hat{y}_{E C}(\tau, \alpha), \breve{y}_{E C}(\tau, \alpha)\right]$, but the slope is steeper. ${ }^{33}$

Finally, agents with income above $\breve{y}_{E C}(\tau, \alpha)$ report all their income, $\gamma^{*}(\tau, \alpha ; y)=1$. For them, (17) simplifies to

$$
\frac{\partial V(\tau, \alpha ; y)}{\partial \tau}=y\left[-u^{\prime}(c)+u^{\prime}\left(d_{N}\right)(1-\beta) \alpha\right]+u^{\prime}\left(d_{N}\right)(1-\beta) \pi \frac{d b(\tau, \alpha)}{d \tau} \leq 0
$$

This formula is quite standard in the political economy of pension systems where evasion and compliance costs are assumed away (i.e. $\gamma=1$ always). The above expression shows that increasing the tax rate creates on the one hand a direct utility cost in terms of reduced first-period consumption but, on the other hand, a marginal utility benefit, due to increased pension benefits in the second period, through both the contributive part (second term above) and the uniform part (third term). We show in Appendix 6.2 that the variation of $\tau^{*}(y)$ with $y$ for these agents may now be ambiguous, in particular because the above expression now includes an additional marginal utility benefit term, $u^{\prime}\left(d_{N}\right)(1-\beta) \alpha y$ which increases in $y$ under Assumption (2) while the first and third terms decrease in $y .{ }^{34}$ Nonetheless, we

\footnotetext{
${ }^{32}$ It is straightforward to show that $\tau^{*}(y)$ is continuous in $\hat{y}_{E C}(\tau, \alpha)$.

${ }^{33}$ Beyond some income level and depending on the levels of parameters, agents may prefer zero taxation. In the following, we exclude that possibility which only constitutes a special case of our model.

${ }^{34}$ Note that evaluating both (18) and (19) (and substituting for (16)) in $\breve{y}_{E C}(\tau, \alpha)$, we obtain the same expressions so
} 
show in the appendix that agents with income $y \rightarrow \breve{y}_{E C}^{+}$prefer a higher tax rate than $\tau\left(\breve{y}_{E C}\right)$, and assuming monotonicity in $\tau^{*}(\alpha ; y)$ for $y>\breve{y}_{E C}$, we find that for these agents, the preferred tax rate is increasing in income. Hence, agents with higher incomes most-prefer higher values of the tax rate. This is a direct consequence of agents with an income above $\breve{y}_{E C}(\tau, \alpha)$ most preferring a higher-than-one value of $\gamma^{*}(\tau, \alpha ; y)$ and of the compliance rate being an increasing function of $y$. These agents would like to transfer more resources to the future than what they actually can: they already fully comply and cannot report more than their true income level. The only way to do so is by choosing a higher tax rate. Since agents with a higher income would like to transfer more to the old age, they prefer a higher tax rate than those with a smaller income. It may even be the case that beyond some sufficiently high income level, agents are in favour of the maximum tax rate possible, i.e. the top of the Laffer curve.

We now derive the voting equilibrium, using our results on the preferred tax rates of agents.

\subsubsection{Majority-voting equilibrium}

One of the difficulties in characterizing the voting equilibrium resides in the fact that whether agents partially or fully comply with the tax system (i.e. depending on whether $y \gtrless \hat{y}_{E C}(\tau, \alpha)$ or $\breve{y}_{E C}(\tau, \alpha)$ ) shape their preference for the tax rate differently so that one cannot use directly the single-crossing condition established by Gans and Smart (1996).

Using the methodology developed by Epple and Romano (1996), we show in Appendix 6.3 that, for agents with $y \leq \breve{y}_{E C}(\tau, \alpha)$, the marginal rates of substitution between $\tau$ and $b(\tau, \alpha)$ are monotonically increasing in $y$. This is also the case for agents with $y>\breve{y}_{E C}(\tau, \alpha)$ provided that the condition that $R_{a}(c) d c / d y<R_{a}\left(d_{N}\right) d d_{N} / d y$ holds. We come back in details on this condition at the end of this section. Therefore, if that condition is satisfied, marginal rates of substitution between $\tau$ and $b$ all vary monotonically in the same direction (i.e. the single-crossing property is satisfied) so that a global Condorcet winner exists, $0 \leq \tau^{V}<1$ which corresponds to the tax rate preferred by a majority of agents.

In order to understand better how the majority voting equilibrium tax rate is obtained, we graph the individuals' preferred tax rate as a function of their income $y$ in Figure $1^{35}$ As it is clear from that figure, we have a case of ends-against-the-middle equilibrium. In that situation, low-income earners together with high-income earners oppose middle-income earners who would prefer smaller tax rates. Indeed, low-income earners are in favour of high tax rates so as to obtain more redistribution from the public pension system (through the flat pension benefit). High-income earners also want higher tax rates as they wish to transfer more resources to the second-period and, the best way to do it is through the

that $\tau^{*}(y)$ is continuous in $\breve{y}_{E C}(\tau, \alpha)$.

${ }^{35}$ Note that this graph is done for exposition purposes. Depending on the value of the parameters (for instance the value of $\chi$ ), it may the case that around $\breve{y}_{E C}$, the preferred tax rate is zero (see footnote 33 ). Also, we may not have straight lines. Yet, this does not affect our explanations about the majority-voting equilibrium. 
pension system which provides a higher return than private savings $(\alpha>\varepsilon)$. Since they already declare all their income, they can only do so by being in favour of a higher tax rate, even if it is at expense of more redistribution which is to their detriment.

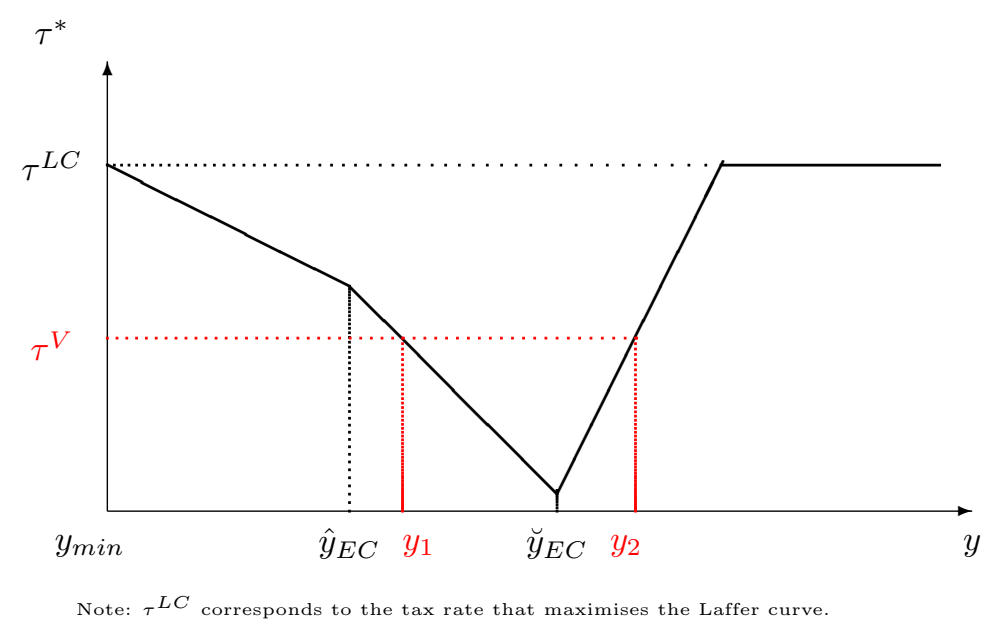

Figure 1: Individuals' preferred tax rates $\tau^{*}(y)$ as a function of their income, $y$.

Therefore, looking at Figure 1, the voting equilibrium $\tau^{V}$ (in red) is such that, at this level, the population is divided in two halves. Half of the population would prefer a strictly higher tax rate, that is a mass $F\left(y_{1}\right)+1-F\left(y_{2}\right)$ of low- and high-income agents, while the other half would prefer a lower tax rate than $\tau^{V}$ and is constituted of agents with middle income, with mass $F\left(y_{2}\right)-F\left(y_{1}\right) \cdot{ }^{36}$ The majority voting equilibrium is formally defined in the following proposition:

Proposition 6 Assume that $\alpha>\varepsilon$ and $R_{a}(c) d c / d y<R_{a}\left(d_{N}\right) d d_{N} / d y$ for individuals with $y>\breve{y}_{E C}(\tau, \alpha)$. The majority voting tax rate $\tau^{V}(\alpha)$ is such that

$$
\tau^{V}(\alpha)=\tau^{*}\left(\alpha ; y_{1}\right)=\tau^{*}\left(\alpha ; y_{2}\right)
$$

where $\tau^{*}\left(\alpha ; y_{1}\right)$ is the solution to (18) evaluated at $y_{1}$ and $\tau^{*}\left(\alpha ; y_{2}\right)$ is the solution to (19) evaluated at $y_{2}$ and, where $y_{1}$ and $y_{2}$ satisfy jointly the following equation

$$
F\left(y_{2}\right)-F\left(y_{1}\right)=1 / 2 \text {. }
$$

Let us finally come back on the condition that $R_{a}(c) d c / d y<R_{a}\left(d_{N}\right) d d_{N} / d y$ for agents with $y>$ $\breve{y}_{E C}(\tau, \alpha)$. If the intensity of the moral cost of compliance, $\chi$ is not too big, using the FOC with respect to $\gamma$, it is possible to show that $c>d_{N}$ (indeed, these agents would like to transfer more resources to

\footnotetext{
${ }^{36}$ Note that $y_{1}$ could equally be located on the first segment of $\tau^{*}$, below $\hat{y}^{E C}$.
} 
the second period). This implies that under Assumption $1, R_{a}(c)<R_{a}\left(d_{N}\right)$ and thus, we show in the Appendix, that a sufficient condition for this inequality to be satisfied is to ensure that $d c / d y<d d_{N} / d y$ or equivalently that

$$
\frac{1-\tau^{V}\left(1+\frac{\alpha}{\pi}\right)}{1+\frac{\varepsilon}{\pi}}<\frac{d s}{d y}
$$

If that condition is not satisfied, a Condorcet winner may not exist and we may not be able to have a stable voting equilibrium. For the reminder of the paper where we are interested in the constitutional choice of $\alpha$, we assume that the above condition is satisfied and that a majority voting equilibrium $\tau^{V}$ exists.

\subsection{Constitutional choice of the level of the Bismarkian factor}

As in Section 3.3, the problem of the Rawlsian social planner consists in maximising the utility of the individual with income $y_{\min }$ :

$$
\begin{aligned}
\max _{\varepsilon<\alpha \leq 1} V\left(\tau^{V}(\alpha), \alpha ; y_{\text {min }}\right) & =u\left(y_{\text {min }}-s^{*}\right) \\
& \left.+\pi\left\{(1-\beta) u\left(\frac{\tau^{V}(\alpha)}{\pi}(1-\alpha) E(\tilde{y})\right)+\frac{\varepsilon}{\pi} s^{*}\right)+\beta u\left(\frac{\varepsilon}{\pi} s^{*}\right)\right\}-\frac{\chi \tau^{V}(\alpha) y}{\beta}
\end{aligned}
$$

where $\tau^{V}(\alpha)$ is defined in Proposition 6. Obviously, $y_{\min }<\hat{y}_{E C}\left(\tau^{V}(\alpha), \alpha\right)$ so that the agent does not report any income. The first order condition of this problem is: ${ }^{37}$

$$
\frac{d V\left(\tau^{V}(\alpha), \alpha ; y_{\min }\right)}{d \alpha}=\frac{\partial V\left(\tau^{V}(\alpha), \alpha ; y_{\min }\right)}{\partial \alpha}+\frac{\partial V\left(\tau^{V}(\alpha), \alpha ; y_{\min }\right)}{\partial \tau} \frac{d \tau^{V}(\alpha)}{d \alpha} \leq 0
$$

where

$$
\begin{aligned}
\frac{\partial V\left(\tau^{V}(\alpha), \alpha ; y_{\min }\right)}{\partial \alpha} & =(1-\beta) \pi u^{\prime}\left(d_{N}\right) \frac{d b\left(\tau^{V}, \alpha\right)}{d \alpha} \\
& =(1-\beta) u^{\prime}\left(d_{N}\right) \tau^{V}(\alpha)\left[(1-\alpha) \frac{d E(\tilde{y})}{d \alpha}-E(\tilde{y})\right]
\end{aligned}
$$

is identical to equation (9) and represents the direct impact of increasing the Bismarkian factor on the utility of the poorest agent, through the flat pension benefit. Here, one needs to take into account two (opposing) forces. On the one hand, increasing $\alpha$ makes overall compliance in the economy vary and therefore the tax base to change (first term in equation 21). If agents had no other choice than reporting their full income, this effect would be absent. If $d E(\tilde{y}) / d \alpha>0$, a higher Bismarkian factor makes agents report more income, increases the tax base and therefore the uniform pension benefit which can be distributed. On the other hand, the second term accounts for the fact that increasing the degree of contributiveness implies less redistribution, which is to the detriment of low-income agents. Hence, this second (redistributive) term pushes toward a lower level of $\alpha$. Like in Section 3.3, evaluating equation

\footnotetext{
${ }^{37}$ We use the envelop theorem for $s^{*}\left(\tau^{V}, \alpha ; y_{\min }\right)$.
} 
(21) in $\alpha=\varepsilon$ and $\alpha=1$, the solution for $\alpha$ should be interior. ${ }^{38}$ Therefore, contrary to standard political economy models of pension systems where agents have no other choice than reporting their true income (for instance, in models à la Casamatta et al. 2000a,b), the fact that compliance depends on the Bismarkian factor, makes the social planner willing to have a positive $\alpha$ while if compliance was fixed, this term would unambiguously lead to $\alpha$ minimum. So, like in the section with no evasion costs, linking contributions to pension benefits through a positive $\alpha$ is a way to increase compliance and thus the utility of the worst-off agent.

The second term in (20) accounts for the indirect impact of $\alpha$ on the utility of the poorest agent, through the majority-voting tax rate. ${ }^{39}$ This term represents, here, how the level of the Bismarkian factor affects the support for the pension system and in turn, the utility of the worst-off agent at the voting equilibrium. The expression $\partial V\left(\tau^{V}(\alpha), \alpha ; y_{\min }\right) / \partial \tau$ is equal to (18) evaluated at $\left(\tau^{V}(\alpha), y_{\text {min }}\right)$ and is positive. Indeed, as shown in Section 4.2.1, the preferred tax rate of the agent with income $y_{\text {min }}$ is decreasing in income so that the worst-off agent prefers a higher tax rate than the one chosen at the majority voting equilibrium. Finally, finding the sign of $d \tau^{V}(\alpha) / d \alpha$ proves rather difficult as one would need to fully differentiate (18) evaluated in $y_{1}$ or (19) evaluated in $y_{2}$ with respect to $\alpha$ and to know the sign of $d^{2} E(\tilde{y}) / d \tau d \alpha$.

To sum up, depending on the size of theses different effects, i.e. redistribution, tax base and political support, described above, the level of $\alpha$ should be more or less important. Yet, there is a priori no reason to believe that it should be either minimum at $\alpha^{R}=\varepsilon$, or maximum (fully contributive) at $\alpha^{R}=1$.

\section{Conclusion}

In standard models of income taxation, tax authorities observe the individuals' wage rate or at least the amount of their earnings. If tax evasion is possible, then an audit technology allows them to recoup a large chunk of tax revenue. Common knowledge of earnings and effective tax enforcement are in general characteristics of advanced economies. In many less advanced economies, informality and selfemployment make it more difficult to enforce a workable tax system, which explains the low level of tax revenue observed there, particularly when the tax base is individual income. In this paper, we show that even under those circumstances public resources mobilization is possible and politically sustainable if taxes are at least partially related to benefits and if the government supplies services for which there are no (good) substitutes in private markets. This is precisely the case of retirement saving whose market returns are often not attractive because of the absence of annuity markets and of the high loading costs

\footnotetext{
${ }^{38}$ The proof is idnetical to that of Appendix 6.1.

${ }^{39}$ This term was absent from the government problem in Section 3.3 because $\tau^{V}$ was independent of $\alpha$.
} 
of the financial institutions.

In this paper, we study the political sustainability of a pension system that has three main features: it is financed by a payroll tax whose base is not observable; it provides benefits that are partially contributive and the marginal return of those social contributions are higher than the financial interest rate. It appears that in the absence of evasion costs, individuals are indifferent to the tax rate chosen as they can perfectly adapt their level of compliance. Yet, the public pension system is found to be partially contributory in order to increase individuals' compliance rate and thus the size of the tax base. This in turn increases the welfare of the least favoured through a higher flat pension benefit. When evasion costs are introduced, perfect substitutability between compliance and taxation breaks down. We obtain a case of ends-against-the-middle voting equilibrium. Low-income agents who want to benefit from intragenerational redistribution, together with high-income individuals who want to transfer more resources to the old age, form a coalition against middle-income agents in favour of high tax rates. The share of the contributive pension pillar will again be chosen so as to increase compliance and thus the tax base, but also in order to increase political support. While the latter reason is standard in the literature, the former (rather obvious) reason has been absent from the political economy literature of pension systems until now.

The policy implication of this paper is rather obvious. Linking (even partially) individual contributions to individual benefits is enough to design a tax system with sufficient political support, to increase tax compliance and ultimately to increase the welfare of the poorest individuals. 


\section{References}

[1] Alm, J., Sanchez, I., and DeJuan, A., 1995. Economic and noneconomic factors in tax compliance, Kyklos 48 (1), 318.

[2] Alm J., G. H. McClelland and W. D. Schulze, 1999. Changing the social norm of tax compliance by voting, Kyklos, 52(2), 141-171.

[3] Allingham M. G. and A, Sandmo, 1972. Income tax evasion: a theoretical analysis, Journal of Public Economics, 1, 323-338.

[4] Bergstrom, T., L. Blume, and H. Varian, 1986. On the Private Provision of Public Goods, Journal of Public Economics, 29, 125-149.

[5] Besley, T., A. Jensen, and T. Persson, 2015. Norms, enforcement and tax evasion, CEPR Discussion Paper No. DP10372.

[6] Bobek, D., Roberts, R., and J. Sweeney, 2007. The social norms of tax compliance: Evidence from Australia, Singapore and the United States, Journal of Busisness Ethics, 74, 49-64.

[7] Borck R., 2004. Stricter enforcement may increase tax evasion, European Journal of Political Economy, 20, 725-737.

[8] Borck R., 2007. Voting, inequality and redistribution, Journal of Economic Surveys, 21(1), 90-109.

[9] Borck R., 2009. Voting on redistribution with tax evasion, Social Choice and Welfare, 32, 439-454.

[10] Casamatta G., H. Cremer, and P. Pestieau, 2000a. Political sustainability and the design of social insurance, Journal of Public Economics, 75, 341-364.

[11] Casamatta G., H. Cremer, and P. Pestieau, 2000b. The political economy of social security, The Scandinavian Journal of Economics, 102(3), 503-522.

[12] Castro, L., and C. Scartascini, 2013. Tax compliance and enforcement in the Pampas. Evidence from a field experiment, IDB Working Paper No. 472. Washington, DC: Inter-American Development.

[13] Epple D. and R. Romano,1996. Ends against the middle: Determining public service provision when there are private alternatives, Journal of Public Economics, 62, 297-325.

[14] Gans, J. S. and M. Smart, 1996. Majority-voting with single-crossing preferences, Journal of Public Economics, 59, 219-237. 
[15] Gaspar, V, L. Jaramillo, and P. Wingender, 2016. Tax capacity and growth: Is there a tipping point?, IMF Working Paper 234.

[16] Gordon R. and W. Li, 2011. Tax structure in developing countries: many puzzles and a possible explanation, Journal of Public Economics, 93(7-8), 855-866.

[17] Guiso, L. and M. Paiella, 2008. Risk aversion, wealth, and background risk, Journal of the European Economic Association, 6(6), 1109-1150.

[18] Holt, CA and SK Laury, 2002. Risk aversion and incentive effects, American Economic Review, $92(5), 1644-1655$.

[19] Karagyozova, T. and P. Siegelman, 2012. Can propitious selection stabilize insurance markets? Journal of Insurance Issues, 35 (2), 121-158.

[20] Kopczuk, W., 2001. Redistribution when avoidance behaviour is heterogenous, Journal of Public Economics, 81, 51-71.

[21] Martinez-Vasquez, J. and J. Alm, 2003. Public Finance in Developing countries and transitional countries: essays in honour of Richard Bird, Cheltenham,UK; Edward Elgar Publishers.

[22] Moore, M. and G. Mascagni, 2014. Tax revenue mobilisation in developing countries: issues and challenges, European Parliament Policy Department Studies Paper.

[23] Slemrod, J., 1998. On voluntary compliance, voluntary taxes, and social capital, National Tax Journal, 51, 485-494.

[24] Torgler and Schneider, 2009. The impact of tax morale and institutional quality on the shadow economy, Journal of Economic Psychology, 30, 228245.

[25] Traxler, C., 2012. Majority voting and the welfare implications of tax avoidance, Journal of Public Economics, 96(1), 1-9.

[26] Wenzel, M., 2004. An analysis of norm processes in tax compliance. Journal of Economic Psychology, 25,213228 .

[27] Wenzel, M., 2005. Motivation or rationalisation? Causal relations between ethics, norms and tax compliance, Journal of Economic Psychology, 26, 491-508. 


\section{Appendix}

\subsection{Variation of $s$ and $\gamma$ in the absence of evasion cost}

Replacing for equation 3 in equation (2), we rewrite the FOC with respect to $s$ as follows:

$$
\frac{\partial E U}{\partial s}=\frac{\varepsilon-\alpha}{\alpha} u^{\prime}(c)+\beta \varepsilon u^{\prime}\left(d_{D}\right)=0
$$

Differentiating this expression with respect to $\alpha$ and evaluating it in $\alpha \rightarrow \varepsilon$, we obtain that $\partial E U^{2} /\left.\partial s \partial \alpha\right|_{\alpha \rightarrow \varepsilon}=$ $-\varepsilon u^{\prime}(c) / \alpha^{2}<0$ so that using the implicit function theorem, $d s /\left.d \alpha\right|_{\alpha \rightarrow \varepsilon}<0$.

Using equation (2), we rewrite (3) as follows:

$$
\frac{\partial E U}{\partial \gamma}=\frac{\alpha-\varepsilon}{\varepsilon} u^{\prime}(c)-\beta \alpha u^{\prime}\left(d_{D}\right)=0
$$

Differentiating it with respect to $\alpha$ and evaluating it in $\alpha \rightarrow \varepsilon$, we obtain

$$
\frac{\partial E U^{2}}{\partial \gamma \partial \alpha}=\left[\frac{u^{\prime}(c)}{\varepsilon}-\beta u^{\prime}\left(d_{D}\right)\right]-\left.\frac{\beta \varepsilon \alpha}{\pi} \frac{d s}{d \alpha}\right|_{\alpha \rightarrow \varepsilon}
$$

Using the FOC with respect to $s$, the first term above is positive and so is the second. Using the implicit function theorem, we can therefore conclude that $d \gamma /\left.d \alpha\right|_{\alpha \rightarrow \varepsilon}>0$. This implies that $d E(\tilde{y}) /\left.d \alpha\right|_{\alpha \rightarrow \varepsilon}>0$.

\subsection{Preferences over $\tau$ of individuals with $y>\breve{y}_{E C}(\tau, \alpha)$}

Differentiating (19) with respect to $y$, we obtain after rearranging terms, the following expression:

$$
\begin{aligned}
\frac{\partial^{2} V(\tau, \alpha ; y)}{\partial \tau \partial y} & =-u^{\prime}(c)\left[1-R_{r}(c) \frac{d c}{d y} \frac{y}{c}\right]+\alpha(1-\beta) u^{\prime}\left(d_{N}\right)\left[1-R_{r}\left(d_{N}\right) \frac{d d_{N}}{d y} \frac{y}{d_{N}}\right] \\
& +(1-\beta) u^{\prime \prime}\left(d_{N}\right) \pi \frac{d b(\tau, \alpha)}{d \tau} \frac{d d_{N}}{d y}
\end{aligned}
$$

which may be positive or negative, so that the preferred tax rate for agents with $y>\breve{y}_{E C}$ may be increasing or decreasing in $y$.

Let us define $\breve{\tau}$ as the preferred tax rate of an agent with income $\breve{y}_{E C}$. It is implicitly defined by equation (18) evaluated in $\breve{y}_{E C}$ and thus, such that

$$
\frac{\chi \breve{y}_{E C}}{\beta}=(1-\beta) \pi u^{\prime}\left(\breve{d}_{N}\right) \frac{d b(\breve{\tau}, \alpha)}{d \tau} .
$$

Evaluating (19) in $\breve{\tau}$, we obtain that for $y \rightarrow \breve{y}_{E C}^{+}$,

$$
\left.\frac{\partial V}{\partial \tau}\right|_{\breve{\tau}, y \rightarrow \breve{y}_{E C}^{+}}=y\left[u^{\prime}\left(d_{N}\right)(1-\beta) \alpha+\frac{\chi}{\beta}-u^{\prime}(c)\right]+\frac{\chi}{\beta}\left(\breve{y}_{E C}-y\right)
$$

where the last term is close to 0 . As for agents with $y>\breve{y}_{E C}^{+}, \gamma^{*}$ is constrained to 1 and $u^{\prime}\left(d_{N}\right)(1-\beta) \alpha+$ $\chi / \beta-u^{\prime}(c)>0$ so that the above expression is strictly positive. Therefore, agents with $y>\breve{y}_{E C}^{+}$prefer a strictly greater tax rate than $\breve{\tau}$. Assuming monotonicity of $\tau^{*}(\alpha ; y)$ on the interval $\left[\breve{y}_{E C}(\tau, \alpha), y_{\max }\right]$, we obtain that $\tau^{*}(\alpha ; y)$ is increasing on this interval. 


\subsection{Single crossing condition with evasion costs}

Let us define the intermediate indirect utility function of an agent with income $y$ as

$$
\begin{aligned}
I(\tau, \alpha ; y) & =u\left(y\left(1-\gamma^{*}(\tau, \alpha ; y) \tau\right)-s^{*}(\tau, \alpha ; y)\right) \\
& +\pi\left\{(1-\beta) u\left(\frac{\tau}{\pi} \alpha \gamma^{*}(\tau, \alpha ; y) y+b(\tau, \alpha)+\frac{\varepsilon s^{*}(\tau, \alpha ; y)}{\pi}\right)+\beta u\left(\frac{\varepsilon s^{*}(\tau, \alpha ; y)}{\pi}\right)\right\}-\frac{\chi \tau y\left(1-\gamma^{*}(\tau, \alpha ; y)\right)}{\beta}
\end{aligned}
$$

where $b(\tau, \alpha)=\frac{\tau}{\pi}(1-\alpha) E(\tilde{y})$. The marginal rate of substitution between $\tau$ and $b(\tau, \alpha)$ has the following general form

$$
M R S(\tau, b)=-\frac{\partial I / \partial \tau}{\partial I / \partial b}=-\frac{\gamma^{*}(\tau, \alpha ; y) y\left[-u^{\prime}(c)+\alpha(1-\beta) u^{\prime}\left(d_{N}\right)\right]-\frac{\chi y\left(1-\gamma^{*}(\tau, \alpha ; y)\right)}{\beta}}{\pi(1-\beta) u^{\prime}\left(d_{N}\right)} \forall y
$$

For agents $y \leq \hat{y}_{E C}(\tau, \alpha)$, it simplifies to

$$
\left.M R S(\tau, b)\right|_{y \leq \hat{y}_{E C}(\tau, \alpha)}=\frac{\chi y}{\pi \beta(1-\beta) u^{\prime}\left(d_{N}\right)}>0
$$

where we replaced for $\gamma^{*}=0$. Since $d d_{N} / d y>0, M R S(\tau, b)$ is increasing in $y$ for agents $y \leq \hat{y}_{E C}(\tau, \alpha)$.

For agents with $\hat{y}_{E C}(\tau, \alpha)<y \leq \breve{y}_{E C}(\tau, \alpha), M R S(\tau, b)$ reduces to the same expression as in (22). The only difference resides in the expression of $d_{N}$ which now includes the contributive part of pension benefit, $\tau \alpha \gamma^{*} y / \pi$. As before, we find that $M R S(\tau, b)$ in increasing in $y$.

Note also that for given $(\tau, b)$, the $M R S(\tau, b)$ of agents with $\hat{y}_{E C}(\tau, \alpha)<y \leq \breve{y}_{E C}(\tau, \alpha)$ is bigger than $M R S(\tau, b)$ of agents with $y \leq \hat{y}_{E C}(\tau, \alpha)$. Hence in the space $(\tau, b)$, the slope of the indifference curve of agents with $\hat{y}_{E C}(\tau, \alpha)<y \leq \breve{y}_{E C}(\tau, \alpha)$ is steeper than that of agents with $y \leq \hat{y}_{E C}(\tau, \alpha)$

For agents with $y>\breve{y}_{E C}(\tau, \alpha)$, we have

$$
\operatorname{MRS}(\tau, b)=-\frac{\partial I / \partial \tau}{\partial I / \partial b}=-\frac{y\left[-u^{\prime}(c)+\alpha(1-\beta) u^{\prime}\left(d_{N}\right)\right]}{\pi(1-\beta) u^{\prime}\left(d_{N}\right)}
$$

First note that condition (19) can be rewritten as

$$
\frac{\partial V(\tau, \alpha ; y)}{\partial \tau}=\frac{\partial I}{\partial \tau}+u^{\prime}\left(d_{N}\right)(1-\beta) \pi \frac{d b(\tau, \alpha)}{d \tau} \leq 0
$$

so that $\partial I / \partial \tau<0$ so as to have an interior solution for $\tau^{*}(\alpha ; y)$. In addition, since $\tau^{*}(\alpha ; y)$ is increasing in $y$, we have, using the implicit function theorem on the above condition that necessarily $\partial^{2} I / \partial \tau \partial y>0$ (since the last term in the above expression decreases with $y$ ).

We also have that $\partial^{2} I / \partial b \partial y=\pi(1-\beta) u^{\prime \prime}\left(d_{N}\right) d d_{N} / d y<0$. Let us now see how the marginal rate of substitution varies with $y$ :

$$
\frac{\partial M R S(\tau, b)}{\partial y}=-\frac{\frac{\partial^{2} I}{\partial \tau \partial y} \frac{\partial I}{\partial b}-\frac{\partial^{2} I}{\partial b \partial y} \frac{\partial I}{\partial \tau}}{\left(\frac{\partial I}{\partial b}\right)^{2}}
$$


where

$$
\begin{aligned}
\frac{\partial I}{\partial \tau} \quad & =-u^{\prime}(c)+\alpha(1-\beta) u^{\prime}\left(d_{N}\right)=-u^{\prime}(c)+\frac{\alpha}{\pi} \frac{\partial I}{\partial b} \\
& \Rightarrow \frac{\partial I^{2}}{\partial \tau \partial y}=-u^{\prime \prime}(c) \frac{d c}{d y}+\frac{\alpha}{\pi} \frac{\partial^{2} I}{\partial b \partial y}
\end{aligned}
$$

Replacing for these expressions at the numerator in (25) and rearranging terms, we find that $M R S(\tau, b)$ is monotonically increasing in $y$ if

$$
-\frac{u^{\prime \prime}(c)}{u^{\prime}(c)} \frac{d c}{d y}<-\frac{u^{\prime \prime}\left(d_{N}\right)}{u^{\prime}\left(d_{N}\right)} \frac{d d_{N}}{d y}
$$

or equivalently, if

$$
R_{a}(c) \frac{d c}{d y}<R_{a}\left(d_{N}\right) \frac{d d_{N}}{d y} .
$$

If $c>d_{N}$, under Assumption $1, R_{a}(c)<R_{a}\left(d_{N}\right)$. Hence, a sufficient condition for the above inequality to hold is that $d c / d y<d d_{N} / d y$, or equivalently that

$$
\frac{1-\tau\left(1+\frac{\alpha}{\pi}\right)}{1+\frac{\varepsilon}{\pi}}<\frac{d s}{d y}
$$

where we replaced for the expressions of $c$ and $d_{N}$ where $\gamma^{*}=1$ for individuals with $y>\breve{y}_{E C}(\tau, \alpha)$. 